\title{
Effect of Acid Treatment in Dye Loading Capacity of Spin Coated ZnO Film
}

\author{
Harka Bahadur Baduwal ${ }^{1}$, Pitamber Shrestha ${ }^{1}$, Dinesh Kumar Chaudhary ${ }^{1,3}$, Deependra Das Mulmi ${ }^{2 *}$, \\ Leela Pradhan Joshi ${ }^{*}$ \\ ${ }^{1}$ Physics Department, Amrit Campus, Tribhuvan University, Kathmandu, Nepal \\ ${ }^{2}$ Nanomaterials Research Laboratory, Nepal Academy of Science and Technology, Khumaltar, Nepal \\ ${ }^{3}$ Central Department of Physics, Tribhuvan University, Kirtipur, Nepal \\ "Email: leela.pradhanjoshi@ac.tu.edu.np,deependra.mulmi@nast.gov.np
}

(Received : 25 June, 2020, Received in Revised form: 6 July, 2020, Accepted : 7 July, 2020, Available online)

\section{Highlights}

- $\mathrm{ZnO}$ is a potential semiconductor material generally used to fabricate devices such as dye sensitized solar cell and gas sensor.

- Spin coating is an economic and effective thin film deposition method where deposition parameters such as thickness and concentration can be easily controlled.

- Acid treatment on $\mathrm{ZnO}$ surface enhanced dye loading capacity

\begin{abstract}
In recent times, the research on $\mathrm{ZnO}$ is growing tremendously, because of its potential use in many applications such as optical devices, dye sensitized solar cell (DSSC), gas sensors and biomedical. ZnO thin films of various thicknesses were prepared by the spin coating method using the zinc acetate precursor with diethanolamine and ethanol. The structural and optical characterizations of as-prepared ZnO films carried out using XRD and UV-Vis spectrophotometer, respectively. The XRD results showed polycrystalline wurtzite structure of $\mathrm{ZnO}$. The average crystallite size of $\mathrm{ZnO}$ as calculated using Debye Scherrer's formula was $26 \mathrm{~nm}$. The optical band gap of $\mathrm{ZnO}$ was found to decrease with film thickness. The dye extracted from the leaves of Tectona Grandis (Sagun) which possesses a high and wide absorbance was used in this experiment. The study on the effect of acid treatment on ZnO films in dye loading showed enhanced absorbance in acid treated $\mathrm{ZnO}$ as compared to untreated $\mathrm{ZnO}$.
\end{abstract}

Key words : ZnO, Polycrystalline structure, Acid treatment, Optical band gap

\section{Introduction}

For some time, investigations on metal oxide semiconductor materials such as Indium Tin Oxide (ITO), Titanium dioxide $\left(\mathrm{TiO}_{2}\right)$, Zinc Oxide $(\mathrm{ZnO})$, Tungsten Oxide $\left(\mathrm{WO}_{3}\right)$, etc. have been significantly rising. Among these $\mathrm{ZnO}$ is a potential compound material because of its interesting physical and chemical properties. Reports also show that it is one of the most extensively researched materials in this industry [Shabbir et al. (2016)] because of its great future scope in a variety of applications including gas sensors, UV detectors and dye sensitized solar cell. Zinc oxide is an abundant, cheap, highly transparent, nontoxic material with high exciton binding energy $(60 \mathrm{meV})$, wide band gap energy $(3.37 \mathrm{eV})$ at room temperature and strong room-temperature

*Corresponding author 
luminescence [Wang et al.(2010); Ozgur et al. (2005); Haufu et. al. (2011)]. ZnO is also an effective UV absorber and emitter too. The optical properties of this compound depend on its underlying intrinsic and extrinsic defects. Generally, it exists as an n-type due to the presence of native defect states such as oxygen vacancies or zinc interstitials. It crystallizes in different structures such as hexagonal wurtzite (WZ), and cubic zinc blende (ZB) and rarely cubic rock salt (RS) [Koster et al. (2015)]. ZnO can be synthesized into various morphologies such as nanostructured thin films, nanorods, nano-sheets, tetrapods, nanoflowers, nanoparticles, nanofibres depending on the method employed [Nurlela et al.(2017); Joshi et al.(2015)]. In ZnO based DSSC, the amount of dye adsorbed into $\mathrm{ZnO}$ plays a vital role. Therefore, this study aims to study the influence of acid treatment on $\mathrm{ZnO}$ film deposited by spin coating technique in dye loading capacity.

\section{Materials and Methods}

The $0.5 \mathrm{M}$ precursor solution was prepared using zinc acetate dihydrate $\left.\left[\mathrm{Zn}\left(\mathrm{CH}_{3} \mathrm{COO}\right)_{2} .2 \mathrm{H}_{2} \mathrm{O}\right)\right]$ precursor with ethanol and diethanolamine (DEA) $\left.\left(\mathrm{C}_{4} \mathrm{H}_{11} \mathrm{NO}_{2}\right)\right]$ with continuous stirring at $(60 \pm 5)^{\circ} \mathrm{C}$ for two hours. The stirred solution appeared transparent and homogenous [Shrestha et al. (2010)]. Addition of DEA increases the solution stability as well as helps in reducing the surface tension so that solution spreads uniformly throughout the substrate to deposit homogeneous film. The $\mathrm{ZnO}$ film was deposited on glass substrate using a spin coater of speed $3000 \mathrm{rpm}$ and spinning time $30 \mathrm{sec}$. Then, the deposited film was preheated at $(110 \pm 5)^{\circ} \mathrm{C}$ for 5 minutes and then post heated at $(450 \pm 5)^{\circ} \mathrm{C}$ for 10 minutes for each coat of the film. The process was repeated to deposit every other coat. After the last coating, the sample was annealed in air at $(450 \pm 5)^{\circ} \mathrm{C}$ for 30 minutes to remove all the unwanted residues. The following schematic diagram (figure 1) summarizes the basic steps of ZnO film disposition.

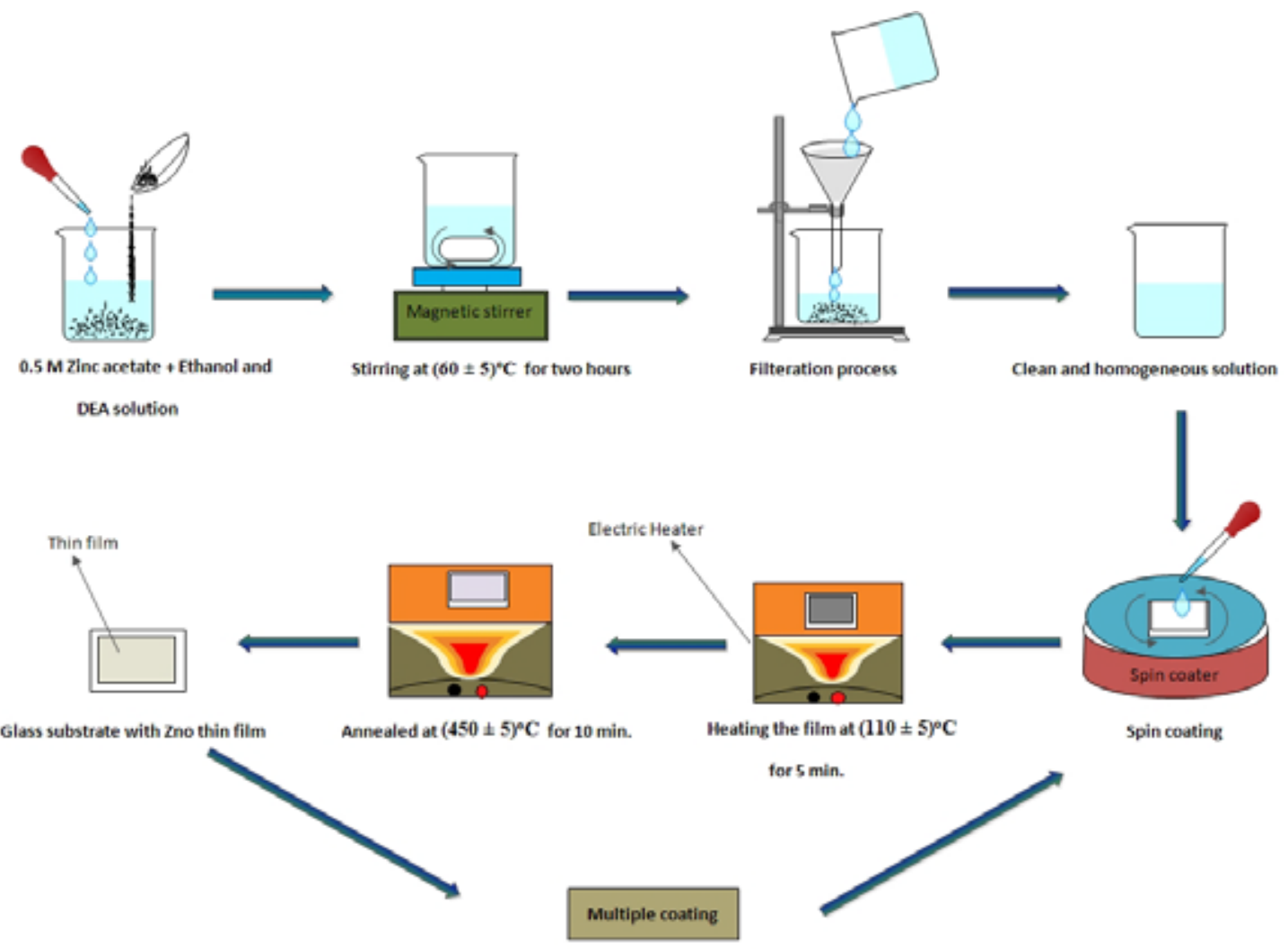

Fig 1: Schematic diagram for ZnO film coating by the spin coating technique

\section{Results and Discussion}

Figures 2(a) and 2(b) illustrated the optical transmittance ( $\mathrm{T} \%$ ) spectra and corresponding band gap of ZnO films of various thicknesses respectively. The film thickness was calculated employing Swanepoel method [Xie et al. (2012)]. The calculations showed that the film thicknesses corresponding to 3, 5, 8, 10, 14, and 16 coats were $557 \mathrm{~nm}, 776 \mathrm{~nm}, 897 \mathrm{~nm}, 1006 \mathrm{~nm}, 1461 \mathrm{~nm}$, 
and $2137 \mathrm{~nm}$ correspondingly. The spectra clearly showed the decrease in transmittance for increasing thickness (figure 2a). The transmittance of 3 coat sample represented by the top most dark black curve was more than $95 \%$, whereas it decreased to about $80 \%$ for 16 coat sample (bottom graph) in figure $2 \mathrm{a}$. The corresponding band gaps were calculated from the Tauc's plot (the graph of $(\alpha h v)^{2}$ versus $h v$ ). Figure 2(b) showed the measured band gap energies of $\mathrm{ZnO}$. Inset of this figure depicted the significant decrease of band gap of $\mathrm{ZnO}$ for increasing film thickness. The band gap of $\mathrm{ZnO}$ decreased from $3.26 \mathrm{eV}$ for 3 coat to $3.17 \mathrm{eV}$ for 16 coat. This trend of decreasing band gap is consistent with reported values [Bouderbala et al. (2008)].
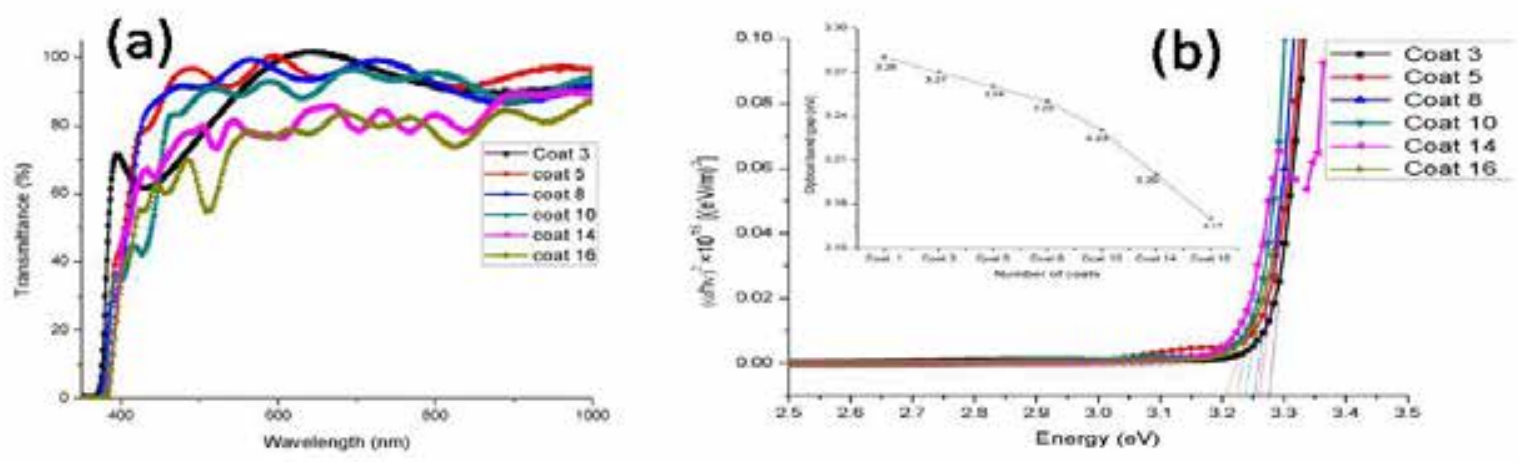

Fig 2: (a) Transmittance and (b) optical band gap of spin coated ZnO films of various thicknesses.

\section{Structural haracterization}

Figure 3 shows the X-ray diffraction (XRD) pattern of $\mathrm{ZnO}$ films of different thicknesses. In the figure, the bottom plot, middle plot and top plot represent the XRD pattern of $16 \mathrm{C}, 14 \mathrm{C}$ and $10 \mathrm{C} \mathrm{ZnO}$ films respectively. Here, $\mathrm{C}$ represents the number of coatings of $\mathrm{ZnO}$. The XRD experiment was performed using X-ray beam, $\mathrm{CuK} \alpha(\lambda=1.5418 \AA)$ in the $2 \theta$ ranged from $25^{\circ}$ to $80^{\circ}$. The multiple peaks obtained in the XRD pattern showed the polycrystalline hexagonal wurtzite structure of ZnO. The intense and sharp peaks were indexed as (100), (002), (101), (102), (110), (103) and (201) with respect to standard peaks of $\mathrm{ZnO}$ from JCPDS file no. 361-451 [Garceset al. (2015)]. The asterisked $(*)$ peak centered at $2 \theta=30^{\circ}$, present in all patterns, which was due to a secondary zinc oxo-acetate phase [Garces et al. (2015)]. A slight shifting of peak positions with film thickness was also visible in the table which may be due to strain of film. The crystalline size (D) of $\mathrm{ZnO}$ was determined using Debye Scherrer's formula $D=\frac{0.94 \times \lambda}{\beta \cos \theta}$ where $\beta$ is the full width half maximum value and $\theta$ is the diffraction angle. The details of calculation of $\mathrm{D}$ for $10 \mathrm{C}, 14 \mathrm{C}$ and $16 \mathrm{C}$ films were illustrated in table 1 . The result showed slight fluctuation in $\mathrm{D}$ because of polycrystalline nature of films. The average $\mathrm{D}$ value of $\mathrm{ZnO}$ was found to be about $26 \mathrm{~nm}$.

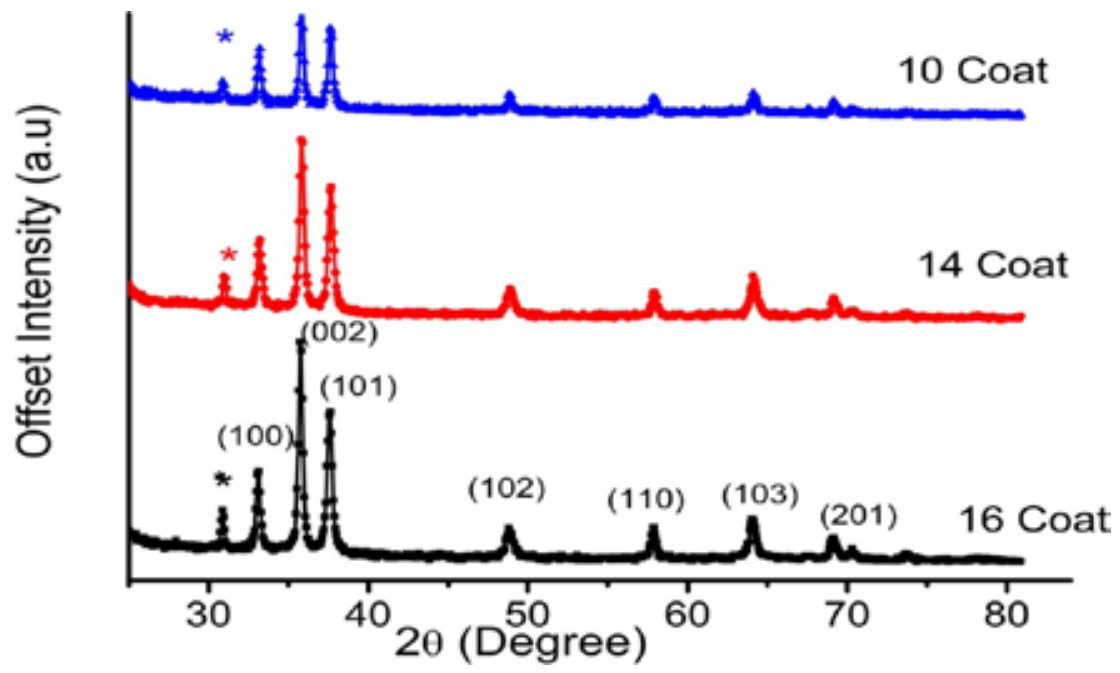

Fig 3: X-ray diffraction profiles of 10 coat, 14 coat, and 16 coat $\mathrm{ZnO}$ films. 
Table 1. The d-spacing, miller indices (hkl) and crystallite size of ZnO films.

\begin{tabular}{|c|c|c|c|c|c|c|}
\hline $\begin{array}{l}\text { No. of Coats of } \\
\mathrm{ZnO}\end{array}$ & $2 \theta$ (Degree) & $\begin{array}{l}\text { Calculated d-spacing } \\
(\AA)\end{array}$ & (hkl) & $\begin{array}{c}\text { Crystallite Size (D) } \\
\text { (nm) }\end{array}$ & $\begin{array}{c}\text { Ave } \\
\mathrm{D}(\mathrm{nm})\end{array}$ & Ave D \\
\hline \multirow{3}{*}{$10 \mathrm{C}$} & 33.1762 & 2.6714 & (100) & 28.38 & \multirow{3}{*}{27.59} & \multirow{9}{*}{$26 \mathrm{~nm}$} \\
\hline & 35.8242 & 2.5055 & (002) & 30.38 & & \\
\hline & 37.6451 & 2.3597 & (101) & 24.03 & & \\
\hline \multirow{3}{*}{$14 \mathrm{C}$} & 33.1910 & 2.6985 & (100) & 24.96 & \multirow{3}{*}{23.99} & \\
\hline & 35.8394 & 2.5047 & (002) & 25.14 & & \\
\hline & 37.6556 & 2.3882 & (101) & 21.87 & & \\
\hline \multirow{3}{*}{$16 \mathrm{C}$} & 33.1129 & 2.7850 & $(100)$ & 27.31 & \multirow{3}{*}{25.85} & \\
\hline & 35.7616 & 2.5104 & (002) & 26.99 & & \\
\hline & 37.5842 & 2.3927 & (101) & 23.26 & & \\
\hline
\end{tabular}

\section{Effect of acid treatment on dye absorption of $\mathrm{ZnO}$ film}

To study the dye absorption capacity of $\mathrm{ZnO}$ film, we first prepared the dye extract solution of Tectona Grandis locally known as Sagun by dissolving well dried crushed leaves of Sagun in pure ethanol. Figure 4 showed the captured absorbance spectrum of dye extract of Sagun leaves. The characteristic feature of this dye is high and broad absorbance in the visible region. The peak observed at $660 \mathrm{~nm}$ was found to be well matched with the characteristics of anthocyanin pigment [Syafinara et al. (2014)]. The other anthocyanin peak at $270 \mathrm{~nm}$ is missing here because of the resolution of our spectrophotometer. As-prepared $\mathrm{ZnO}$ films were readily etched in acidic solutions to study dye loading capacity [Mariano et al. (1963)]. The color of the film quickly changed to dark green after immersing into acid solution accompanied by a significant increase in absorption (figure 5) due to the binding of anthocyanin to the oxide surface. The absorbance spectra of five coated (5 C) $\mathrm{ZnO}$ only, $\mathrm{ZnO}$ with dye and acid treated $\mathrm{ZnO}$ with dye were shown in figures 5(a) Likewise, absorbance spectra of ten coated $(10 \mathrm{C}) \mathrm{ZnO}, \mathrm{ZnO}$ with dye and acid treated $\mathrm{ZnO}$ with dye were shown in figure 5(b). Both the figures clearly showed an increase in absorbance of acid treated $\mathrm{ZnO}$ with dye in the wavelength range $400 \mathrm{~nm}$ to $650 \mathrm{~nm}$. This is due to the availability of more absorption centers as created by acid treatment. In general, the surface atoms of thin films are tightly bound to three adjacent atoms in the bulk material. The partial positive and negative charges of the dangling bonds at the $\mathrm{Zn}$ and $\mathrm{O}$ terminated on surfaces which can easily be attacked by hydronium $\left(\mathrm{H}^{+} \mathrm{O}\right)$ ions of acidic solution [Gatos (1961); Jo et al. (2005); Hupkes et al. (2012)].According to the dangling bond model high etch rates are achieved for O-terminated surfaces. Thus, deep craters are etched at those sites which absorb more dyes than untreated sample. Acid treatment in $\mathrm{ZnO}$ film enhanced the dye loading capacity that is useful in the fabrication of low cost and high performance natural dye sensitized solar cells.

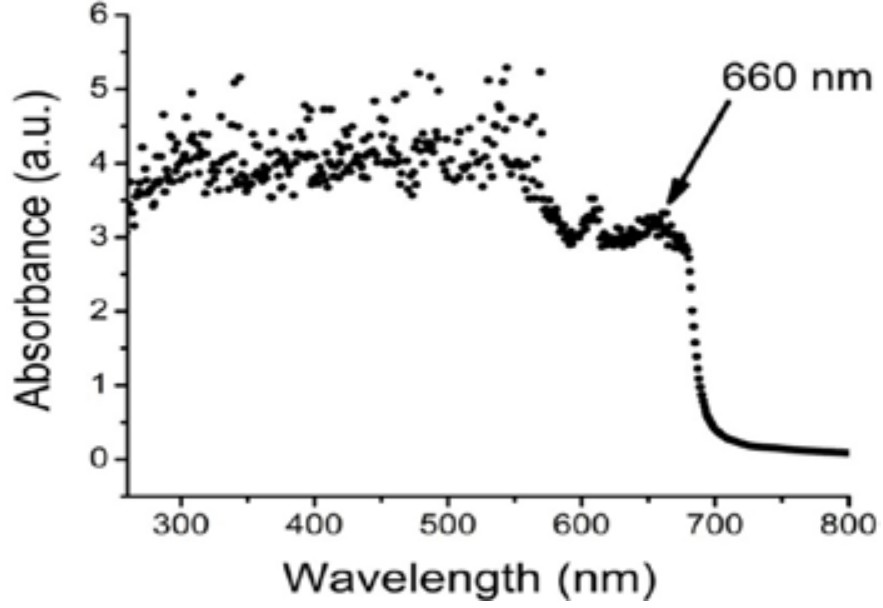

Fig 4: Absorbance spectrum of Tectona Grandis (Sagun). 

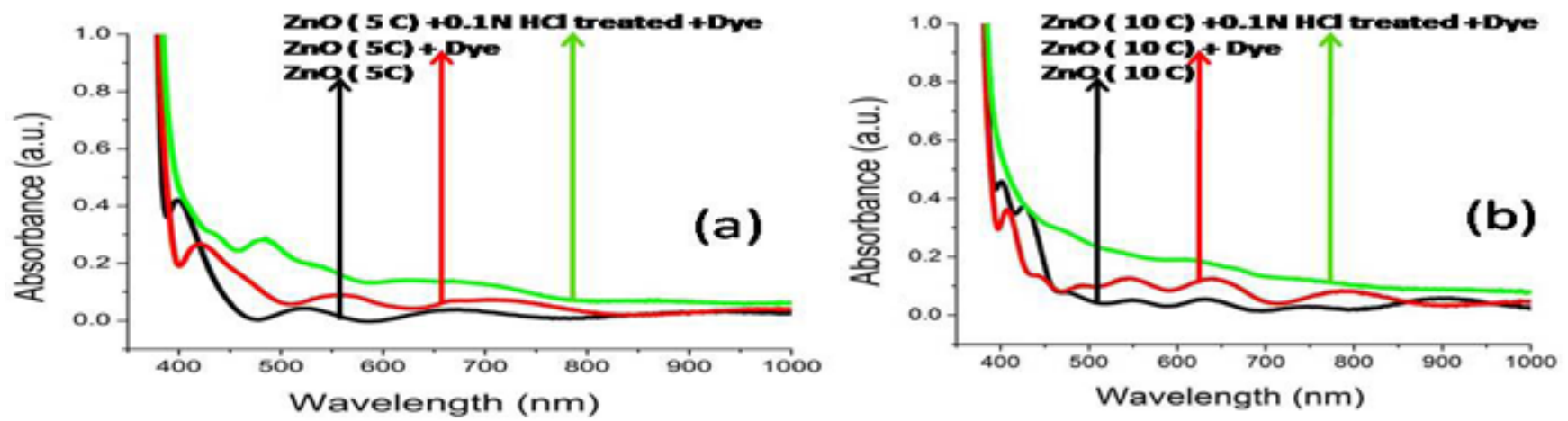

Fig 5: Absorbance spectra of ZnO films with (a) 5C, and (b) $10 \mathrm{C}$ where black, red and green curves represent absorbance of bare ZnO, dye loaded $\mathrm{ZnO}$ and dye loaded into acid treated $\mathrm{ZnO}$ respectively.

\section{Conclusions}

Thin films of $\mathrm{ZnO}$ with various thicknesses were prepared using spin coating method. The presence of multiple peaks of XRD pattern confirms the polycrystalline nature of $\mathrm{ZnO}$. The average crystallite size, about $26 \mathrm{~nm}$ of $\mathrm{ZnO}$ was independent of film thickness. The optical analysis showed the decrease of band gap of $\mathrm{ZnO}$ film for increasing film thickness. The absorbance of dye extract of leaves of Tectona Grandis was high and wide in the visible range which is advantageous for fabrication of natural DSSC. Ultimately, results on absorbance measurement showed an enhancement with acid treated $\mathrm{ZnO}$ film than untreated films due to formations of more craters in acid treatment of $\mathrm{ZnO}$.

\section{Acknowledgments}

The authors would like to thank University Grants Commission (UGC), Nepal and Research Centre, Tribhuvan University for providing partial financial support to complete this research work at Amrit Campus, TU, Nepal.

\section{References}

Bouderbala, M., Hamzaoui, S., Amrani, B., Reshak, A. H., Adnane, M., Sahraoui, T. and Zerdali, M. 2008. Thickness dependence of structural, electrical and optical behaviour of undoped $\mathrm{ZnO}$ thin films. Physica B 403: 3326-3330.

Garces, F. A., Budini, N., Koropecki, R. R. and Arce, R.D. 2015. Structural analysis of ZnO:(Al, Mg) thin films by X-ray diffraction.Procedia Mater. Sci.8: 551-560.

Gatos,H. C. 1961. Dangling bonds in III-V compounds. J. Appl. Phys. 32(7):1232-1234.

Haufu,Z., Shugang, Y., Hanfa, L. and Changkun, Y. 2011. Preparation and characterization of transparent conducting ZnO:W films by DC magnetron sputtering. J. Semicond. 32(4): 1-4.

Hupkes, J., Owen, J. I., Pust, S.E. and Bunte, E. 2012. Chemical etching of Zinc Oxide for thin-film silicon solar cells. Chem Phys Chem. 13: 66-73.

Jo, W., Kim, S.-J. and Kim, D.-Y. 2005. Analysis of the etching behavior of ZnO ceramics.

.Acta Mater. 53(15): 4185-4188.

Joshi, L.P., Subedi, K.P., Dangol, L., Shrestha, P. and Shrestha, S. P. 2015. Preparation and characterization of Zinc Oxide nanosheets for Dye-sensitized solar cell using Vitis Vinifera Dye Extraction. Intern. J. of Resear. and Develop. Org. 2: $1-15$. 
Koster,R. S., Fang,C. M., Dijkstra,M. Blaaderen, A. and Huis, M. A. 2015. Stabilization of rock salt ZnO nanocrystals by lowenergy surfaces and Mg additions: A First-Principles Study. J. Phys. Chem.119: 5648-5656.

Mariano, A. N. and Hanneman, R. E. 1963.Crystallographic polarity of ZnO crystals. J. Appl. Phys. 34(2): 384-388.

Nurlela, R. W. and Gunlazuardi, J. 2017. Natural dye sensitizer from cassava (Manihot utilissima) leaves extract and its adsorption onto $\mathrm{TiO}_{2}$ photo-anode. IOP Conf. Ser.: Mater. Sci. Eng. 188: 012047-012054.

Ozgur,U., Alivov, Y. I., Liu,C., Teke,A., Reshchikov, M. A., S. Dogan, S., Avrutin, V., Cho, S. J. and Morkoc,H. 2005. A comprehensive review of $\mathrm{ZnO}$ materials and devices. J. Appl. Phys. 98: 1-103.

Shabbir, M., Islam, S., Bukhari, M. N., Rather, L. J, Khan, M. A. and Mohammad, F. 2016. Chitosan: sustainable and environmental friendly resource for textile industry. Text. Clot. Sustain.2, 233-252.

Shrestha, S.P., Ghimire, R., Nakarmi, J.J., Kim, Y., Shrestha, S., Park, C. and Boo J. 2010. Properties of ZnO: Al films prepared by spin coating of aged precursor solution. Bull. Korean Chem. Soc. 31: 112-115.

Syafinara, R.., Gomesha, N., Irwantoa, M., Fareqa, M. and Irwana, Y. M. 2014. Potential of Purple Cabbage, Coffee, Blueberry and Turmeric as nature based dyes for Dye Sensitized Solar Cell (DSSC). Energy Procedia.79: 799-807.

Wang, X. L., Dou, S. X. and Zhang,C. 2010. Zero-gap materials for future spintronics, electronics and optics. NPG Asia Mater. 2(1):31 -38.

Xie, G.C., Fanga, L., Penga, L.P., Liua, G.B., Ruan, H.B, Wua, F. and Kong, C.Y.2012. Effect of In-doping on the optical constants of $\mathrm{ZnO}$ thin films. Phys. Procedia. 32: 651-657. 